\title{
Kinematic Alignment Technique for Total Hip Arthroplasty
}

\author{
Charles Rivière, Ciara Harman, Oliver Boughton, \\ and Justin Cobb
}

\section{Key Points}

- Kinematically aligning hip components consists of restoring the native hip anatomy, plus or minus adjusting cup orientation and design to account for an abnormal spine-hip relationship.

- By restoring close-to-physiological hip biomechanics and preventing poor dynamic component interaction, the KA technique may be advantageous by improving prosthetic function, patient satisfaction and reducing the risk of revision surgery.

- The individual spine-hip relationship, which is radio-clinically defined, is now becoming a new parameter to consider when planning a hip replacement.

- Defining the spine-hip relationship of each patient is more informative than

C. Rivière $(\bowtie)$

The MSK Lab-Imperial College London,

White City Campus, London, UK

South West London Elective Orthopaedic Centre,

Epsom, UK

C. Harman

South West London Elective Orthopaedic Centre,

Epsom, UK

O. Boughton · J. Cobb

The MSK Lab-Imperial College London,

White City Campus, London, UK

e-mail: o.boughton@imperial.ac.uk;

j.cobb@imperial.ac.uk just assessing their sagittal lumbo-pelvic kinematics, and is likely to result in more refined surgical planning.

- The kinematic implantation may be performed freehand, and therefore at low cost, by relying on intra-articular anatomical landmarks.

\subsection{Introduction}

\subsubsection{The Concept}

The concept was developed as a consequence of the increasing awareness that dynamic function is, in addition to improved arthroplasty materials and component positioning, a significant factor in total hip arthroplasty stability and lifespan [1-4].

The kinematic alignment (KA) technique for hip replacement consists of restoring the native hip anatomy, plus or minus adjusting the cup orientation and design to account for an abnormal spine-hip relationship (SHR) [1, 5, 6] (Fig. 11.1). In other words, it is a combination of both an anatomical hip reconstruction (proximal femur, acetabular anteversion and hip centre of rotation) and a kinematic cup alignment technique [7]. While the former enables a close-to-physiological peri-prosthetic soft tissue balance for optimum prosthetic function and patient satisfaction, the latter could reduce the risk of poor dynamic 
Fig. 11.1 Figure

illustrating the restoration of the native anatomy (right) when kinematically aligning (KA) total hip components (left). COR centre of rotation, $T A L$ transverse acetabular ligament, SHR spine-hip relationship

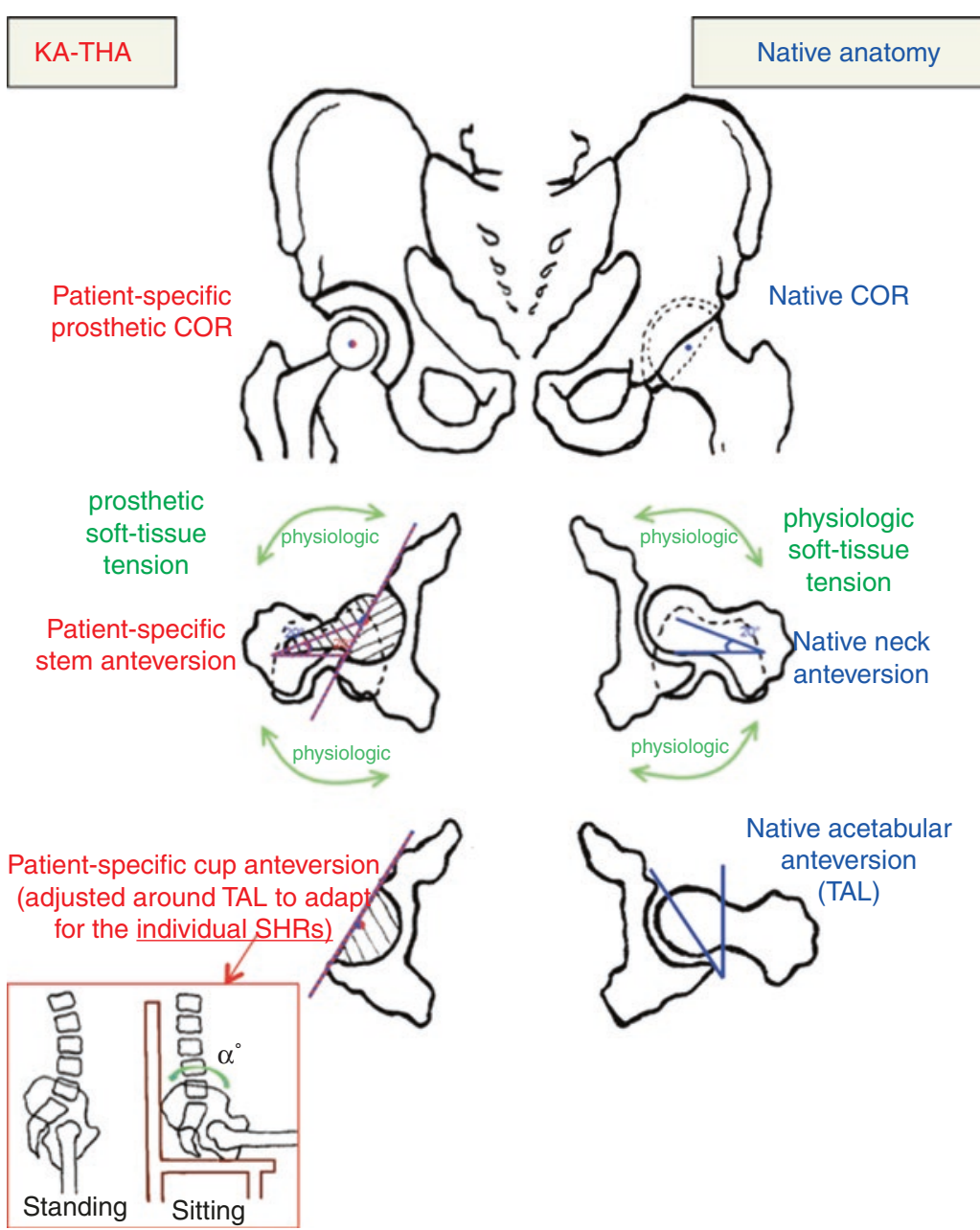

component interaction during activities of daily living (ADLs) for optimal implant lifespan. By generating a component interaction that is the best compromise between the standing and sitting positions, kinematically aligned hip components hopefully prevent the occurrence of an aberrant component interaction during ADLs, which may be clinically advantageous. This personalized technique applies to both stemmed (THR) and resurfacing (HR) implants, and is even more pertinent at a time when arthroplasty patients are becoming younger, with higher demands and expectations, in addition to a longer life expectancy [8].

The KA concept takes the individual SHR into consideration in order to determine a targeted adjustment of an anatomical cup positioning [6]
(Fig. 11.2). The subsequent plan can be well executed without the need for costly technology. Several reported strategies exist for taking the individual lumbo-pelvic sagittal kinematics into consideration when implanting hip components $[9,10]$, however they differ slightly from the reported KA concept presented here $[1,5,6]$. With other strategies, following radiographic estimation of the individual lumbo-pelvic kinematics, a targeted cup orientation is defined and then executed with the use of intraoperative technological tools $[9,10]$. The radio-clinical definition of the individual SHR provides information on the patient's lumbo-pelvic kinematics, the presence of a spine-hip and/or hip-spine syndrome [11], the spinal sagittal balance status and, lastly, the constitutional biomechanical spine 


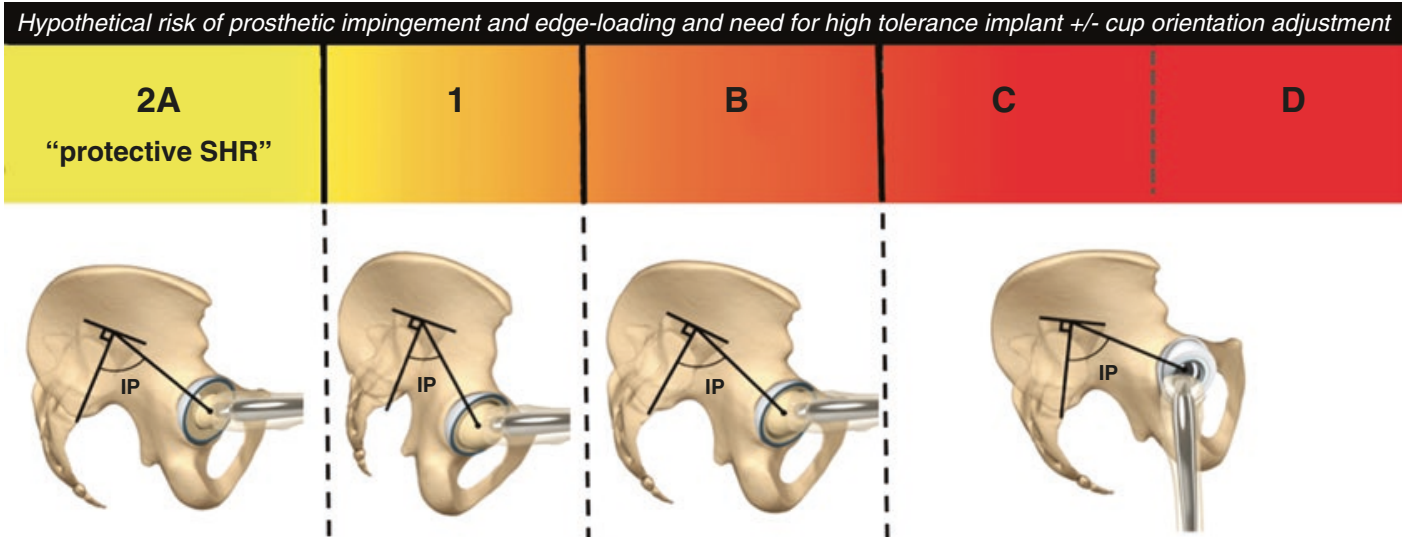

Fig. 11.2 Simplified Bordeaux classification of spinehip relationship (SHR) with types $2 \mathrm{~A}, 1, \mathrm{~B}, \mathrm{C}$ and D. The risks of poor functional component interaction and the need for cup adjustment (design and orientation) are likely to increase from left (yellow colour) to right (red colour) profile (this depends on the pelvic incidence value and whether the patient is a spine or hip user) [1]. Kinematically aligning hip components is therefore a sophisticated concept that leads to more refined THR planning.

\subsubsection{The Rationale}

Gold-standard techniques for implanting hip components have generated good long-term outcomes, but have failed to solve the common residual complications affecting modern prosthetic hip patients [8]. Those conventional techniques are designed to be biomechanically sound, do not aim to accurately reproduce the native hip anatomy [12], and traditionally involve either systematic [12] or combined component orientation [13] approaches. Despite successful reports, complications related to poor component interaction such as edge loading [14], articular impingement [15-17] and prosthetic instability [18] remain. Interestingly, the higher surgical precision achieved by means of technological assistance (computer navigation and robotics) has failed to significantly improve clinical outcomes of conventional THA [19]. Another interesting finding is the poor correlation observed between the static standing/supine radiographic cup orientation and the risk of conventional THA instability [20-22]. Those last observations challenge the accuracy of such conventional implantation philosophies.

Alternative anatomic alignment techniques for implanting hip prostheses have successfully been promoted over the past few decades, but they have also failed to lessen the burden of residual complications from which prosthetic hip patients suffer [23-25]. These techniques aim to restore the native hip anatomy (with the exception of the acetabular inclination), and are best characterised through the following examples: use of the transverse acetabular ligament (TAL) for aligning the cup [23], hip resurfacing [26] and neck-sparing total hip replacement (neck anchorage short femoral stem designs) [27]. The rationale for anatomical implantation lies in the following:

1. The limited ability to calculate an ideal cup orientation from preoperative images due to the multiple acetabular functional orientations and femoro-acetabular interplay combinations that individuals display during ADLs [28, 29].

2. Most hip pathologies causing degeneration (e.g. cam impingement, most pincer impingements, low-grade dysplasia, avascular necrosis, genetic, protrusio, all causes of hip arthritis, synovial diseases) are automatically corrected when modern high-tolerance (high 
Fig. 11.3 Classification of abnormal lumbopelvic sagittal kinematics. PI Pelvic incidence

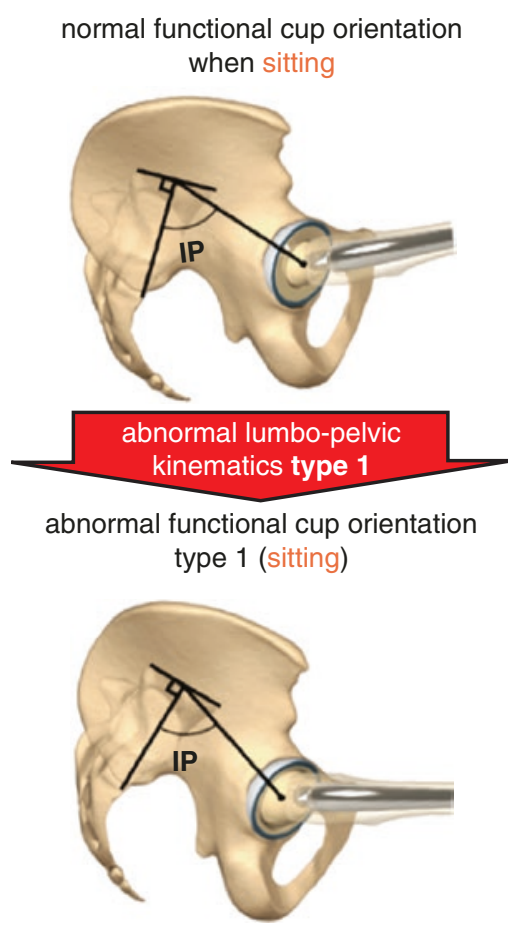

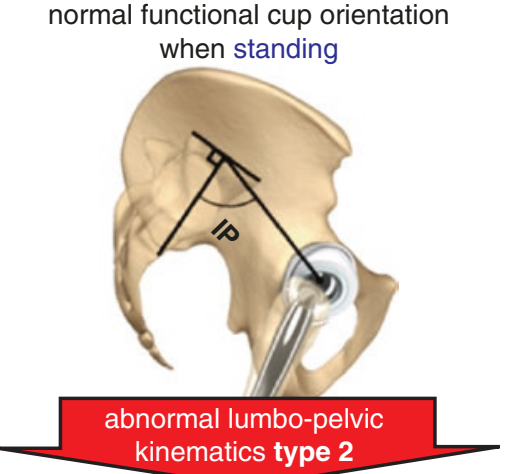

abnormal functional cup orientation type 2 (standing)

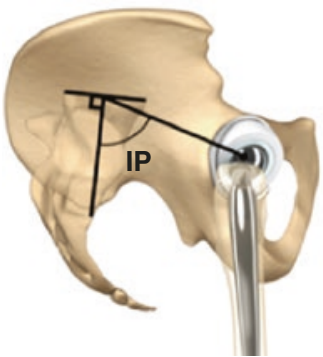

head-neck ratio) hip components are anatomically positioned.

3. The fact that restoring the native hip anatomy improves prosthetic hip function and patient satisfaction through the generation of a more physiological peri-prosthetic soft tissue balance and prosthetic hip kinematics [16, 30, 31].

Similar to conventional techniques, despite having been reported as safe and suitable for the majority of patients, several complications remain with anatomically implanted hip prostheses, primarily related to poor dynamic interaction of components [23, 27, 32]. Many of these may be explained by a lack of consideration for the functional aspect of the acetabular orientation, or in other words, through neglecting the individual lumbo-pelvic sagittal kinematics/SHR [32].

The presented kinematic alignment technique takes into consideration the functional acetabular orientation to allow more refined THA planning, and hopefully improved clinical outcomes of prosthetic hip patients $[1,5,6]$. Neglecting the sitting component interaction, along with the fact that many complications occur when sitting, probably partly explains the poor correlation observed between the static standing/supine radiographic cup orientation and the risk of conventional THA instability [20-22].

The classification of abnormal lumbo-pelvic kinematics (Fig. 11.3) and SHRs (Table 11.1) [1], along with methods for defining the individual SHR (Fig. 11.4) and for determining the amount of cup adjustment needed (design [1] and orientation [6]) (Table 11.2) has previously been published. There are primarily two abnormal lumbo-pelvic kinematics (Fig. 11.3), the first being related to individuals who sit without sufficiently retroverting their pelvis (type 1 abnormal lumbo-pelvic kinematics - SHR B), and the second is the result of an ageing process with a stiff degenerated spine, locking the pelvis in a chronic retroverted position when the patient stands (type 2 abnormal lumbo-pelvic kinematics - SHR C/D) [1]. Both abnormal lumbo-pelvic kinematics (type 1 [32, 33] and type 2 [34-37]) adversely affect prosthetic hip patient outcomes (spine-hip syndrome), as they alter the sitting (type 1) or standing (type 2) acetabular orientation 
Table 11.1 Simplified Bordeaux classification of spine-hip relationship and their diagnostic criteria

\begin{tabular}{|c|c|c|c|c|c|c|}
\hline \multirow{3}{*}{$\begin{array}{l}\text { LPC } \\
\text { SHR }\end{array}$} & \multicolumn{6}{|c|}{ Simplified Bordeaux classification of SHR } \\
\hline & \multirow{2}{*}{$\begin{array}{l}\text { Flexible LPC } \\
\text { A }\end{array}$} & \multicolumn{5}{|c|}{ Stiff LPC } \\
\hline & & 1 & $\mathrm{~B}$ & $\mathrm{C}$ & $\mathrm{D}$ & Fused spine \\
\hline Diagnosis & $\begin{array}{l}\mathrm{PI}>30^{\circ} \\
\text { No standing } \\
\text { PI-LL mismatch } \\
>10^{\circ} \text { delta SS } \\
\text { from standing to } \\
\text { sitting }\end{array}$ & $\begin{array}{l}\text { PI } \\
<30^{\circ}\end{array}$ & $\begin{array}{l}\text { No standing } \\
\text { PI-LL mismatch } \\
<10^{\circ} \text { delta SS } \\
\text { from standing to } \\
\text { sitting }\end{array}$ & $\begin{array}{l}\text { Standing } \\
\text { PI-LL } \\
\text { mismatch } \\
\text { Normal SVA }\end{array}$ & $\begin{array}{l}\text { Standing } \\
\text { PI-LL } \\
\text { mismatch } \\
\text { Abnormal } \\
\text { SVA }\end{array}$ & $\begin{array}{l}\text { Instrumented or } \\
\text { biologically fused } \\
\text { spine }\end{array}$ \\
\hline
\end{tabular}

SHR Spine-Hip Relationship, LPC Lumbo-Pelvic Complex, PI Pelvic Incidence, LL Lumbo-Lordosis, SS Sacral Slope, SVA Sagittal Vertical Axis distance

Fig. 11.4 Algorithm for defining the individual spine-hip relationship (SHR). PI pelvic incidence, $L L$ lumbar lordosis, SS sacral slope

\section{Steps for defining Individual SHR}

Step 1: Patient with sagittal spinal imbalance? Clinical diagnosis after exclusion, via the Thomas test, of a severe fixed flexion hip deformity (hip-spine syndrome)

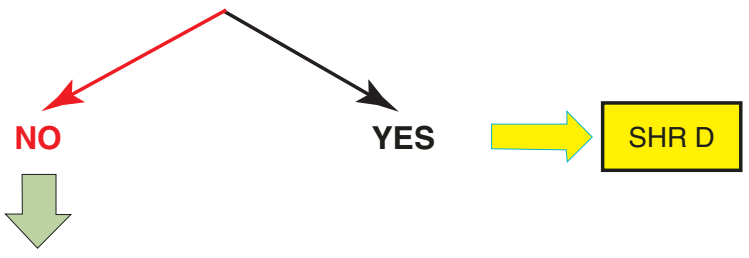

Step 2: Lateral standing lumbo-pelvic radiograph:

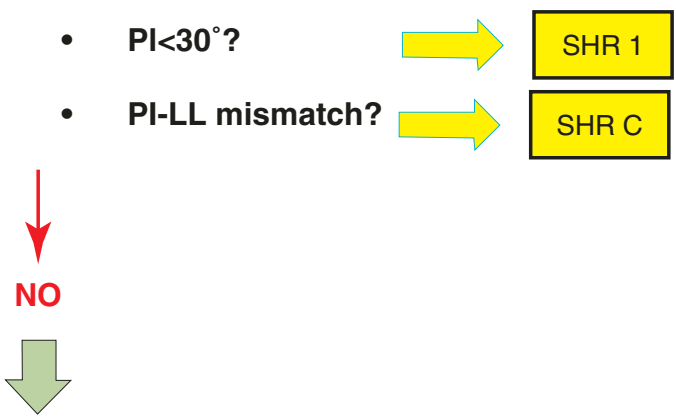

Step 3: Comparison of lateral standing \& sitting lumbo-pelvic radiographs:

- Delta SS $<10^{\circ}$ ? SHR B

- Delta $S S>10^{\circ}$ with proportional delta LL?

\section{SHR A}

and component interaction. When implanting such patients, it is important to adjust the cup (orientation and design) in order to compensate for the abnormal functional acetabular orientation. The appreciation and understanding of the individual SHR is therefore critical for the next stage of improvements in hip arthroplasty.

\subsubsection{Intended Benefits}

Compared to conventional techniques for replacing a hip, kinematically aligned hip components may potentially improve prosthetic hip function and lifespan because of the potential for improved anatomical reconstruction and interaction of 
Table 11.2 Algorithm for adjusting the cup orientation to account for the individual spine-hip relationship (SHR)

\begin{tabular}{l|l|l|l|l|l|l}
\hline \multirow{2}{*}{ SHR } & \multicolumn{4}{l}{ Simplified Bordeaux classification of SHR } & \multicolumn{3}{l}{ B } & C & Fused spine \\
\cline { 2 - 5 } $\begin{array}{l}\text { Cup } \\
\text { anteversion } \\
\text { adjustment }\end{array}$ & $\begin{array}{l}\text { None } \\
\text { (cup parallel } \\
\text { to TAL) }\end{array}$ & $\begin{array}{l}\text { Increased cup anteversion by } \\
3.5^{\circ} \\
\text { (relative to TAL) for every } \\
10^{\circ} \text { of lack of pelvic } \\
\text { retroversion when sitting } \\
\text { (normal pelvic retroversion } \\
\left.\text { when sitting }=20^{\circ}\right)\end{array}$ & $\begin{array}{l}\text { Reduced cup anteversion by } \\
3.5^{\circ} \text { (relative to TAL) for } \\
\text { every } 10^{\circ} \text { of excessive } \\
\text { standing pelvic retroversion } \\
\text { (normal standing SS }=75 \% \\
\text { of PI) }\end{array}$ & $\begin{array}{l}\text { Idem B or C, } \\
\text { depending on } \\
\text { position of fusion } \\
\text { and residual } \\
\text { flexibility }\end{array}$ \\
\hline $\begin{array}{l}\text { Cup } \\
\text { inclination } \\
\text { adjustment }\end{array}$ & $\begin{array}{l}\text { None } \\
\text { (radiographic } \\
\left.\text { target: } 40^{\circ}\right)\end{array}$ & $\begin{array}{l}\text { Don't change your freehand technique for cup inclination as the additional cup } \\
\text { anteversion will increase the radiographic cup inclination } \\
\left.\text { (radiographic target: } 40^{\circ} \text { to } 50^{\circ}\right)\end{array}$ & \\
\hline
\end{tabular}

TAL Transverse Acetabular Ligament, APP Anterior Pelvic Plane

components during ADLs, respectively. The anatomic reconstruction should generate a close-tophysiological peri-prosthetic soft-tissue balance and hip biomechanics, which may be clinically advantageous, and hopefully result in improved prosthetic hip function and patient satisfaction $[16,30,31,38]$. The better interaction of components during ADLs may decrease the risk of complications related to articular impingement and edge loading (e.g. instability, liner breakage, accelerated wear, squeaking and cup loosening) in addition to reducing the risk of revision, thus benefiting both the patient and society [8]. The benefits are even more likely considering that kinematic implantation is reproducible due to the fact that articular anatomical landmarks (TAL, femoral length and offset measures) are used for setting the components' orientation [39]. The relevance of the KA technique is further accentuated by the fact that implanted patients are now becoming younger and therefore have higher demands and expectations, as well as a longer life expectancy.

\subsubsection{Indications and Contraindications}

The kinematic alignment technique for hip components is applicable to most patients, as anatomically reconstructed hips are known to be successful [23, 26], and the kinematic cup adjustment aims to compensate for clinically deleterious abnormal spine-hip relations (SHRs) [34, 35, 40]. A series of 41 unselected consecutive KA THA patients has shown acceptable radiographic supine cup orientation and excellent early-term clinical outcomes (no complications, high function and satisfaction) [6].

Determining which hip anatomical variants should not be reproduced, due to biomechanical inferiority, remains unclear. It seems unreasonable to restore hip pathoanatomies resulting from a post-traumatic malunion, a poorly performed acetabular or femoral osteotomy, a protrusio acetabulum or severe developmental hip disease (high-grade dysplasia or Legg-Calvé-Perthes), as those anatomies are not the result of the development of a harmonious interaction between the acetabulum and the proximal femur. Should we anatomically restore the fraction $(\approx 15 \%)$ of osteoarthritic hip patients that have an atypical femoral neck and/or acetabular anatomical orientation [12, $41,42]$ ? The functionality of the acetabulum and femoral neck orientations $[1,12,43]$, in addition to the complex femoro-acetabular interplay [44, 45], makes it difficult to predict which hip anatomies may or may not be suitable for anatomic implantation. The fact that good long-term clinical outcomes have been reported with anatomically reconstructed hip patients $[23,26]$, even in those with degeneration secondary to a low-grade dysplasia [46], indicates anatomical implantation is probably reliable in the vast majority of patients.

In patients with severely stiff, degenerated hip(s), accurate definition of the individual SHR may not be possible, thus compromising kinematic planning. In the former situation, a severely stiff hip is likely to dictate the spine motion (or lumbopelvic kinematics) required between standing and sitting positions, thus making post-implantation lumbo-pelvic kinematics difficult to predict [28, 47-49]. In the latter case, bilateral degenerated hips 
make it difficult to discriminate clinically between true (resulting from severe spine degeneration) and false (caused by bilateral fixed flexion deformity hip-spine syndrome) spinal sagittal imbalance [11]. In these clinical situations, the pre- and postoperative SHR may significantly differ as a result of the correction of the hip-spine syndrome. Given that the post-implantation SHR is difficult to predict, kinematically aligning hip components in these scenarios should be done with caution.

\subsection{Planning a Kinematic Implantation}

Radio-clinical definition of the individual SHR: A thorough clinical examination is the first step in defining the individual status for spinal sagittal balance and degenerated hip flexibility. As previously stated, patients with a severely stiff hip or bilateral degenerated hips may not be the best candidates for a kinematic implantation. The second step is radiographic evaluation based on the analysis of lateral lumbo-pelvic views in functional standing and sitting positions (Fig. 11.5). This enables the definition of the individual pelvic incidence (PI), the diagnosis of spine degeneration (standing PI-lumbar lordosis mismatch) and an estimation of the lumbo-pelvic kinematics (delta sacral slope and delta lumbar lordosis) (Fig. 11.5) [1]. Ideally, the imaging should be performed with EOS $^{\text {TM }}$ bi-dimensional images (Biospace, Paris, France), but, if not available, conventional radiographs are sufficient. The methods for defining the individual SHR and the subsequent cup adjustment (design and orientation) have previously

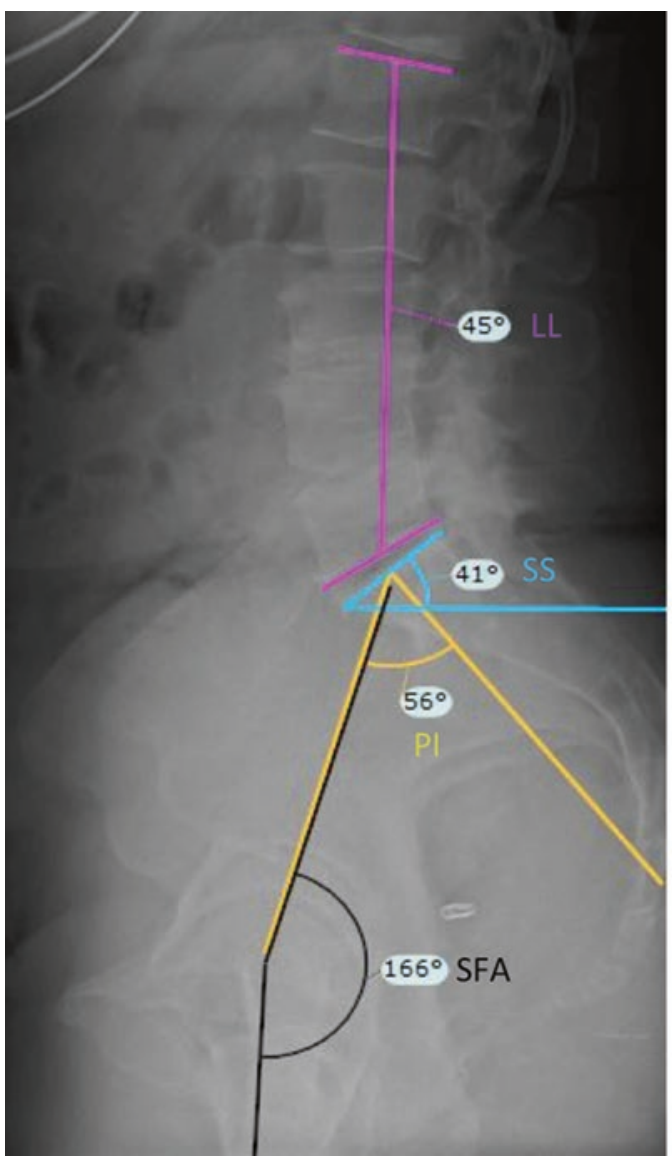

Fig. 11.5 Preoperative lateral lumbo-pelvic standing (left) and sitting (right) radiographs showing measurements of spino-pelvic parameters in both positions: PI

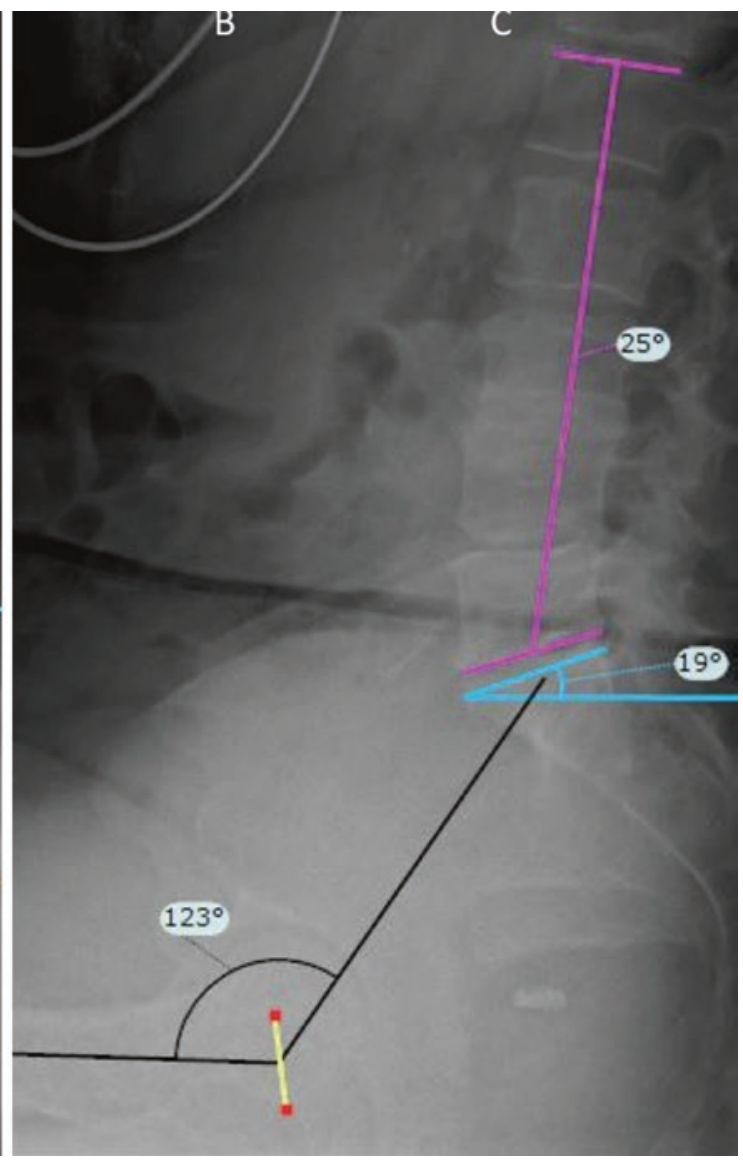

pelvic incidence, SS sacral slope, $L L$ L1-L5 lumbar lordosis and $S F A$ - sacro-femoral angle 
been published $[1,6]$ and are illustrated in Fig. 11.4 and Table 11.2, respectively.

Why take the individual pelvic incidence into consideration when planning a KA THA? The PI is an anatomical and biomechanical pelvic parameter that determines the sagittal spine morphology and kinematics (Fig. 11.6), in addition to the timing and severity of developing a spine-hip syndrome in the case of severe spine degeneration [1]. As a result, the PI has been shown to influence the functional acetabular orientation
$[42,50]$ and the risk of prosthetic instability [34, 35]. There may be two explanations for this:

- Patients with an abnormally low PI $\left(<30^{\circ}\right)$ have a constitutionally low lumbar lordosis, and they are likely to primarily flex their hips (constitutional hip users - SHR type 1) when switching between standing and sitting positions (Fig. 11.6). This use of a large hip cone of mobility is likely to adversely affect prosthetic hip outcomes as a result of the increased

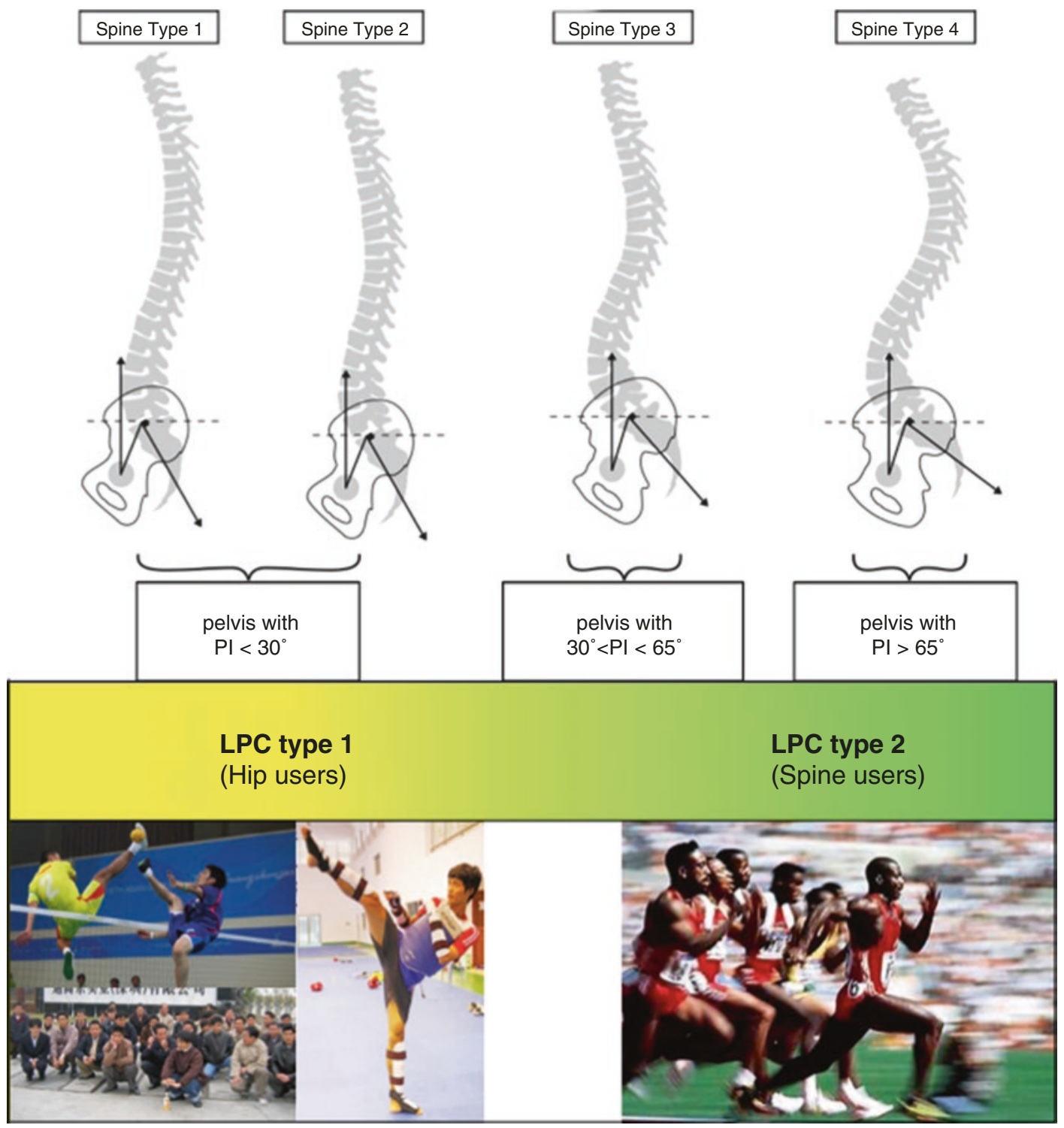

Fig. 11.6 Role of the pelvic incidence on the spine morphology and kinematics. $P I$ pelvic incidence, $L P C$ lumbopelvic complex 
risks of articular impingement- and edgeloading-related complications. In the event of spine degeneration, these patients will rapidly decompensate their sagittal spinal imbalance but only moderately modify their hip biomechanics (slight deterioration of the standing acetabular orientation and standing femoroacetabular interaction, plus slight increase of hip use, causing a moderate spine-hip syndrome). In the event of a hip replacement, such patients (SHR 1) may benefit from a high-tolerance cup design, plus or minus a slight adjustment of the cup orientation to compensate for the poor functional acetabular orientation resulting from the abnormal lumbo-pelvic kinematics (constitutionally stiff spine).

- Patients with a normal PI are likely to display more spine motion, and therefore less hip movement, when switching from a standing to sitting position (constitutional spine users). The use of a low hip range of motion for ADLs is likely to be protective with regard to the risks of prosthetic impingement, edge loading and instability [1]. However, in the situation of severe spine ageing, the loss of spine flexibility may have a severe clinical adverse impact as it significantly modifies the hip biomechanics: there is dramatic deterioration in the standing acetabular orientation and standing femoro-acetabular interaction, plus a significant increase in hip use, causing a severe spine-hip syndrome. This hypothesis may partly explain the higher PI $[34,35]$ and more severe spine degeneration (SHR types $2 \mathrm{C}$ and 2D) [35-37] that characterise unstable prosthetic hip patients. In the event of a hip replacement, such SHR 2D patients may benefit from a high-tolerance cup design in addition to a moderate cup orientation adjustment to compensate for their aberrant standing acetabular orientation.

Defining the cup adjustment (design and orientation) (Table 11.2): Planning a radiographic cup inclination below $50^{\circ}$ is important to prevent poor standing and walking component interaction (superior edge loading). In contrast, the kinematic cup anteversion relative to the anterior pelvic plane cannot be planned as its value primarily depends on the TAL orientation, which cannot be estimated on simple preoperative radiographs. For this specific reason, the KA concept does not aim to plan cup orientation relative to the anterior pelvic plane, but rather the amount of cup orientation adjustment, relative to anatomical positioning (TAL), that is needed to compensate for an abnormal SHR [6]. The key points to understand the rationale supporting the adjustment are:

1. The adjustment should first target the cup orientation, as the restoration of the native proximal femur anatomy and hip centre of rotation is key to producing clinically advantageous, close-to-physiological prosthetic hip kinematics.

2. A cup orientation adjustment is made when, and in addition to, the use of a higher tolerance cup design (larger head [51, 52], dual mobility [53]) is likely to be insufficient in compensating for the poor functional acetabular orientation resulting from the abnormal lumbo-pelvic kinematics .

3. The cup orientation adjustment aims only to compensate for half of the functional acetabular orientation abnormality that results from the poor lumbo-pelvic kinematics (compromised orientation).

4. The algorithm for calculating the amount of cup adjustment needed (Table 11.2) was determined based on the following published observations: the average posterior pelvic tilt from standing to sitting for healthy patients is approximately $20^{\circ}[54,55]$, for every $10^{\circ}$ of pelvic tilt there is a change of radiographic cup orientation by approximately $7^{\circ}$ (anteversion) and $3^{\circ}$ (inclination) [56], and the normal standing sacral slope angle approximates $75 \%$ of the PI angle [57].

\subsection{Performing a Kinematic Implantation}

Kinematically aligning hip components can be performed with or without technological assistance, the latter method having been shown to 
Fig. 11.7 Intraoperative steps for performing kinematic implantation of total hip components with manual instrumentation. TAL transverse acetabular ligament

\section{SURGICAL TECHNIQUE}

\section{KA-THA}
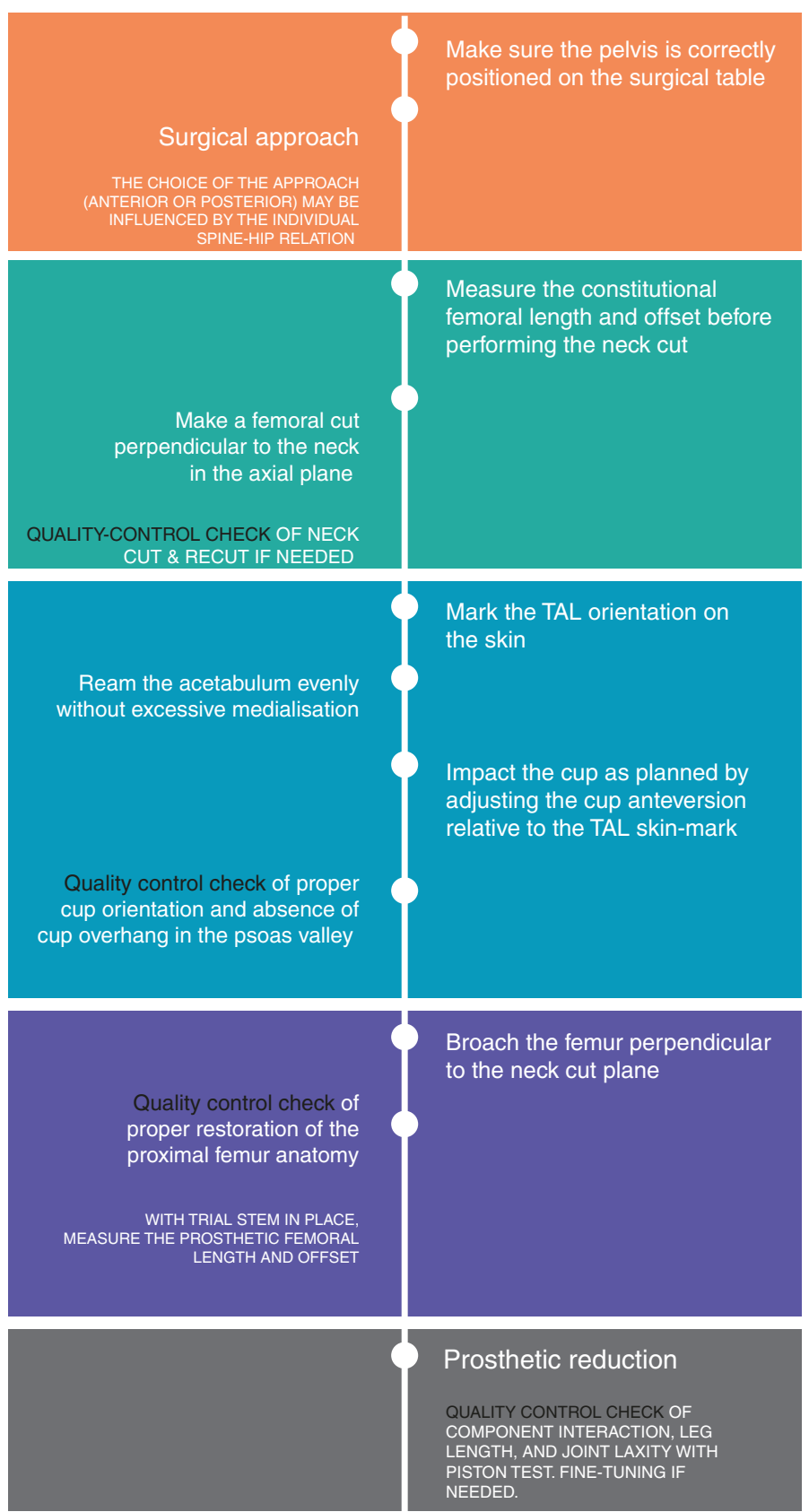

NEEDED.

Final components implantation \& closure 

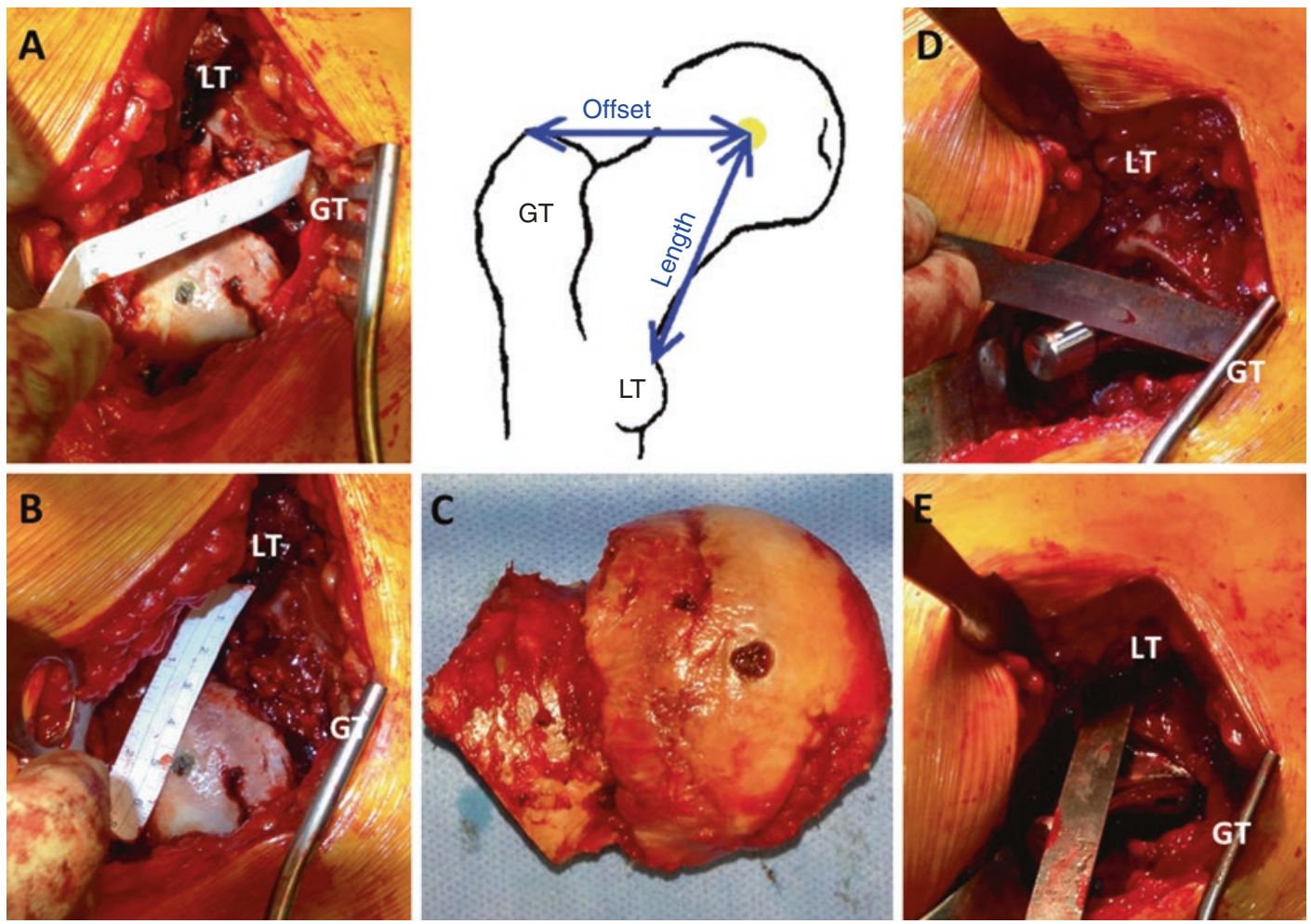

Fig. 11.8 Ruler technique for assisting restoration of femoral length and medial offset. The distances between the centre of the femoral head and the greater trochanter (GT- femoral neck offset - (a) and lesser trochanter (LT femoral neck length $-(\mathbf{b})$ are measured after dislocation,

be reliable [6]. The freehand KA technique relies on intraoperative anatomical landmarks (e.g. TAL, femoral neck cut) and measurements (e.g. femoral offset and length), whilst following a precise stepwise execution as shown in Fig. 11.7. The femoral reconstruction aims to be anatomic, following a modified calliper technique as described by Hill et al. [58], which helps to restore the original femur length and medial offset (Fig. 11.8). Restoration of the constitutional femoral neck anteversion is done by ensuring a cut perpendicular to the neck (Fig. 11.9a, b) and broaching perpendicular to the neck cut (Fig. 11.9c). Regarding the acetabular reconstruction, the medio-lateral positioning (or depth) of the cup is adjusted by reaming the acetabulum not excessively medially, but rather sufficiently to restore the native hip centre of rotation as templated before the operation before the femoral neck cut. This serves to assess the quality of the femoral reconstruction with the trial stem in place (d and e). After the neck cut, ensure you accurately define the centre of the femoral head (c)

(Fig. 11.10). The cup inclination is adjusted with the use of the classic alignment rod, in addition to positioning the inferior and superior parts of the cup relative to the inner border of the TAL and the acetabular roof, respectively. The cup anteversion is set relative to the TAL orientation, which has been marked on the skin (Fig. 11.11), as previously described by Meftah et al. [59], and is impacted perpendicular to it (anatomic and kinematic cup positions are identical) unless slight adjustment is needed (anatomic and kinematic cup positions differ) (Fig. 11.11). Whilst freehand anatomic and kinematic implantations are unlikely to be technically demanding [39], it is probable that technology (3D planning, assistive devices for precise implantation and intraoperative quality control tools) would be of value in further improving its reliability. 

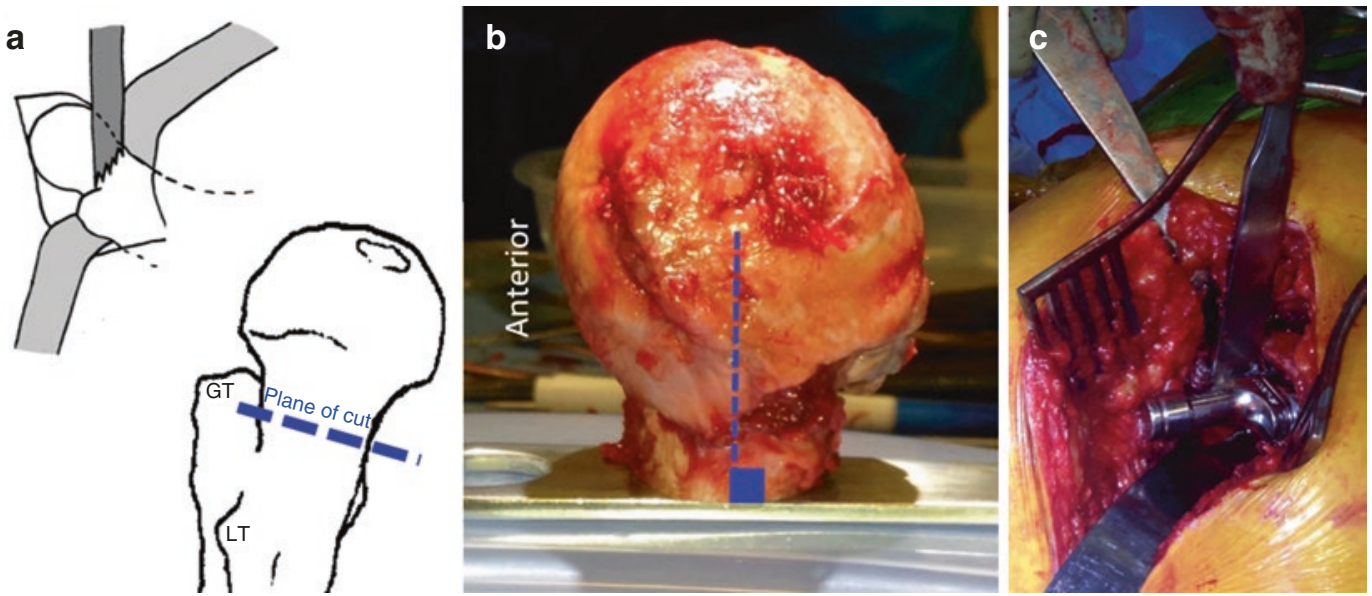

Fig. 11.9 The femoral cut is made perpendicular to the femoral neck in the frontal and axial planes (a). Following the neck cut, check the cut was properly executed in the
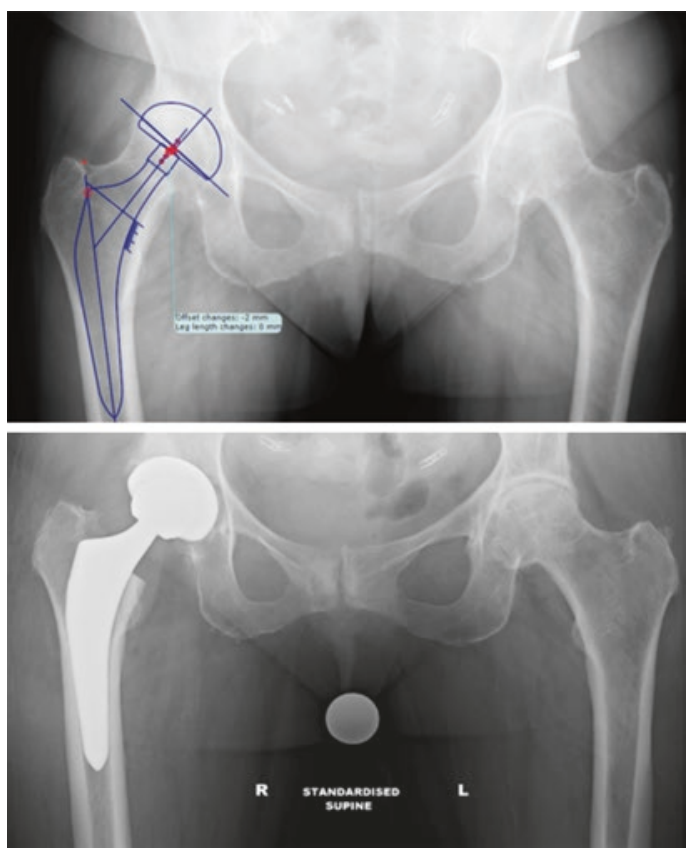

Fig. 11.10 Pelvic radiographs showing the planned (above) and performed (below) medio-lateral positioning of the cup

\subsection{Clinical Evidence}

A single clinical study [6], a matched casecontrol design on prospectively collected clinical data, concluded that KA-THAs were overall safe, efficacious and not inferior to the conventional axial plane (b). When broaching the femur and inserting the trial stem, ensure you are perpendicularly aligned to the femoral neck cut plane (c)

THAs in the short term. The authors compared 41 consecutive freehand KA-THAs with 41 conventional mechanically aligned THAs with 1 year of follow-up. The KA patients had a more anatomical restoration and a higher supine radiographic cup anteversion, but with a similar proportion of cup orientations within the Lewinnek safe zone. Both techniques of alignment had similar excellent clinical outcomes with high function (mean Oxford Hip Score at 43), no instability or other aseptic complications and an average patient outcome satisfaction score of 95.4/100 and 89.5/100 for KA and MA patients, respectively.

\subsection{Future Developments}

The concept of kinematically aligning hip components is only at its early stage, with many refinements yet to be made. There are a few limitations which currently affect the quality of the kinematic planning, and thus need to be investigated through further research: firstly, the difficulty in accurately defining the preoperative individual SHR. This is due to the existence of various lumbo-pelvic kinematics in an individual between and within (intra-individual variability) multiple ADLs [29, 55, 60], and due to a frequent concomitance with a stiff osteoarthritic hip that may dictate some spine motion [11]. Secondly, it 

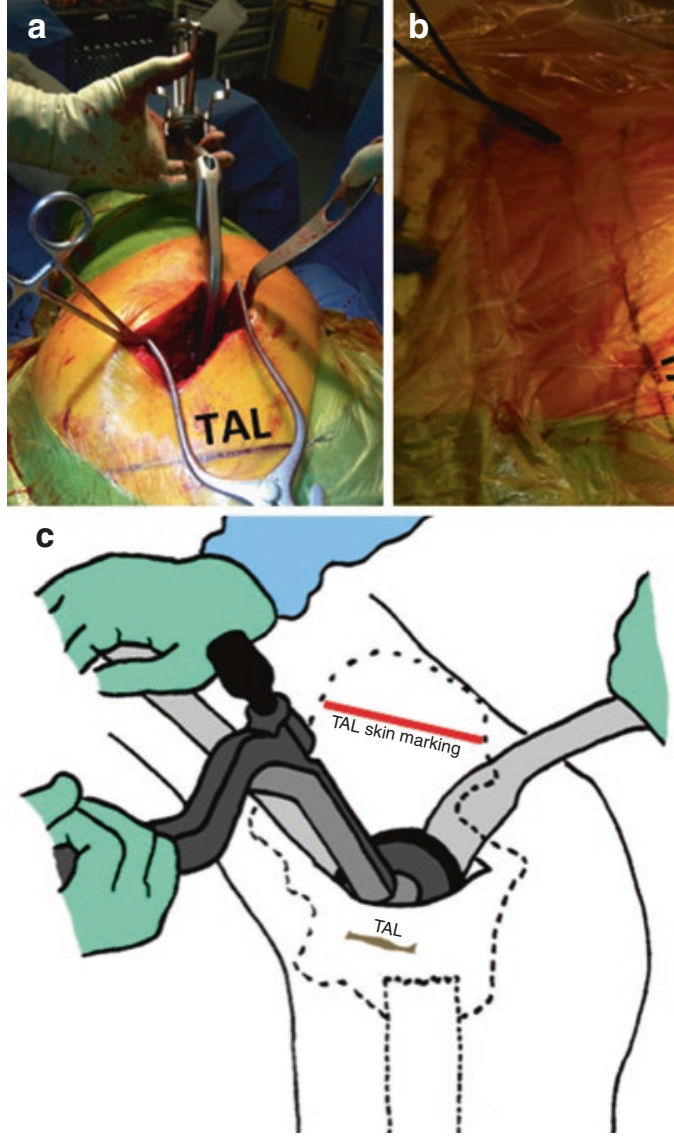

Fig. 11.11 Skin marking is made parallel to the transverse acetabular ligament (TAL) either through posterior (a) or direct anterior (b) approaches. The TAL skin mark

is difficult to anticipate the post-implantation individual SHR that will occur after correction of the hip soft tissue contracture [12, 28, 47, 49]. Lastly, it is the difficulty in anticipating the agerelated SHR changes that will occur over years.

\subsection{Conclusion}

Kinematically aligning hip components involves restoring the native hip anatomy, plus or minus adjusting the cup (orientation and design) to account for an abnormal spine-hip relationship. By restoring close-to-physiological hip biomechanics and preventing poor dynamic component interaction, the KA technique may be advanta- geous by improving prosthetic function, patient satisfaction and reducing the risk of revision. The kinematic planning is based on the radioclinically defined individual spine-hip relationship, and the implantation may be performed freehand by relying on intra-articular anatomical landmarks, incurring no additional technological costs. Further research is needed to refine the KA technique.

\subsection{Case Illustration}

Kinematic implantation on patients having SHR 2A, B and D are illustrated in Figs. 11.12, 11.13 and 11.14 , respectively. 

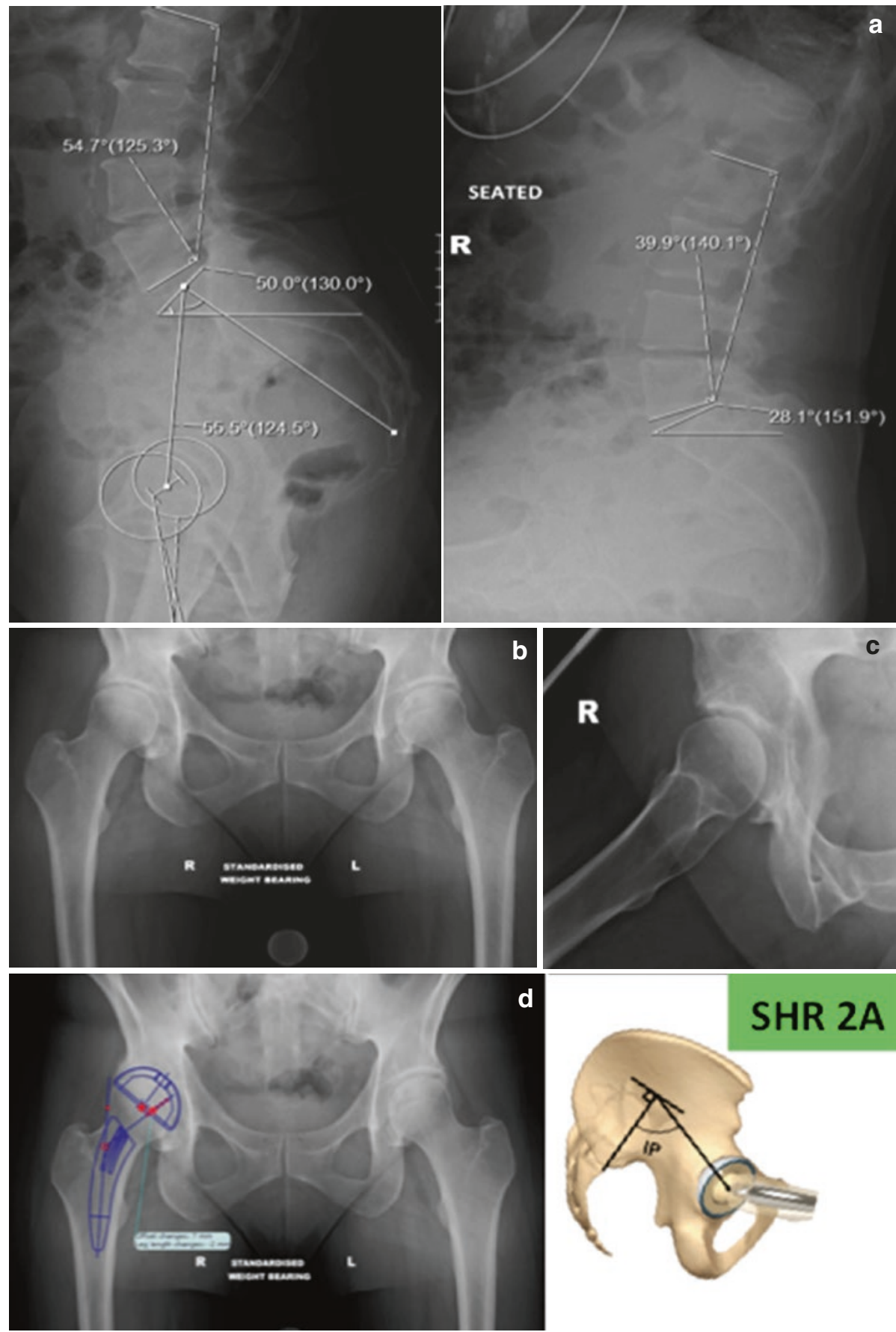

d

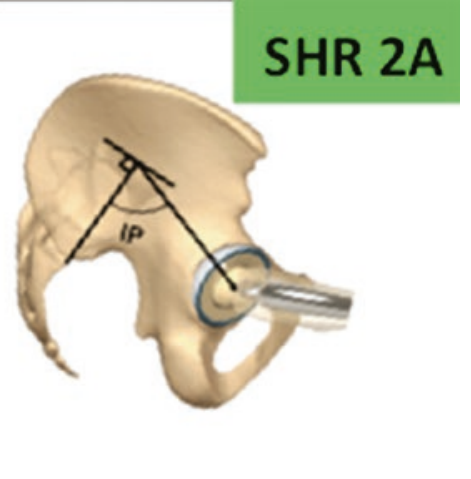

Fig. 11.12 A 58-year-old patient with a right osteoarthritic hip and a spine-hip relationship type $2 \mathrm{~A}$ (normal pelvic incidence $\approx 56^{\circ}$, normal standing lumbar lordosis $\approx 55^{\circ}$, normal delta sacral slope $\approx 22^{\circ}$ ). The cup and stem (neck-sparing design for subsequent neck anchorage) were then kinematically implanted without the need for a cup orientation adjustment, and a $36 \mathrm{~mm}$ ceramic bearing was used. Pre-operative lateral lumbo-pelvic standing (left) and sitting (right) radiographs with spino-pelvic parameter measurements (a). Preoperative standing pelvic (b) and lateral cross-leg osteoarthritic hip views (c). Total hip replacement planning using Traumacad ${ }^{\mathrm{TM}}$ software (d). Post-operative supine pelvic (e) and lateral Dunn (f) radiographs with the kinematically implanted prosthetic hip 

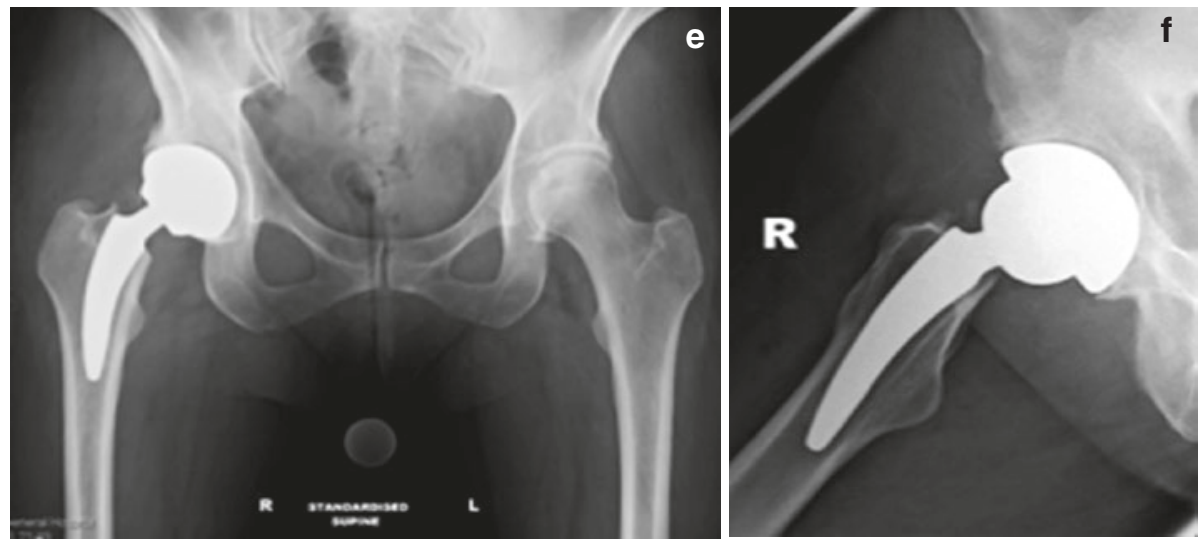

Fig. 11.12 (continued)

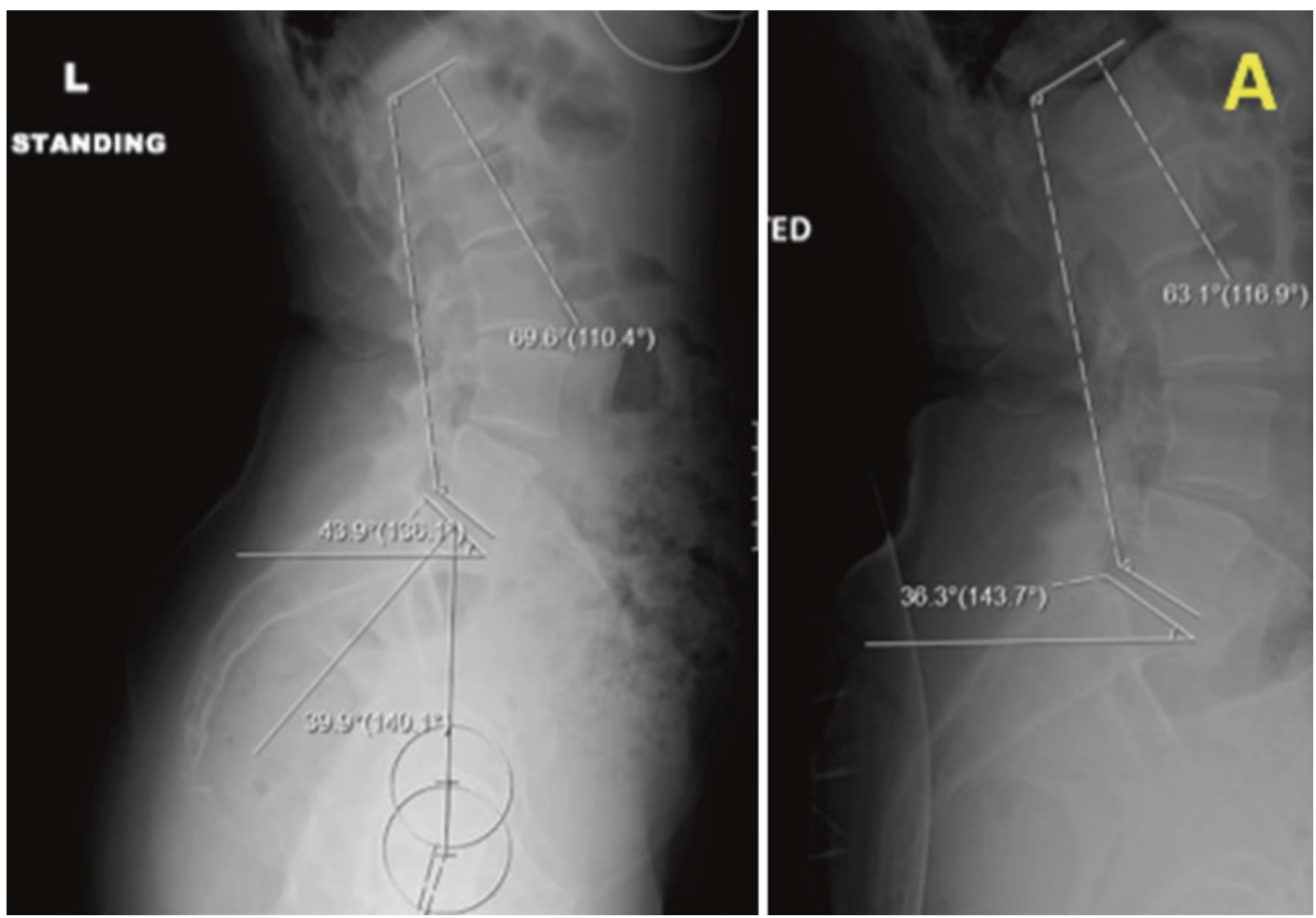

Fig. 11.13 A 62-year-old patient with bilateral osteoarthritic hips secondary to protrusio and a spine-hip relationship type $\mathrm{B}$ (normal pelvic incidence $\approx 44^{\circ}$, high standing lumbar lordosis $\approx 69^{\circ}$, low $8^{\circ}$ delta sacral slope). In the event of a replacement, anatomically aligning components would have been suboptimal considering the risk of complications (posterior edge loading and posterior instability) related to poor interaction between components when sitting. In order to reduce those risks, the patient received a KA-THA performed through a direct anterior approach, preserving the integrity of posterior hip soft tissue. The stem was anatomically implanted; the cup orientation was slightly adjusted with an additional $4^{\circ}$ of anteversion relative to the transverse acetabular ligament. On both hips, the centre of rotation was not lateralised and no medial acetabular bone grafting was performed; this is because the protrusion was slight and no significant bony overhang was observed at the periphery of the cups during trialing and after final implantation. Pre-operative lateral lumbo-pelvic radiographs (a) in standing (left) and sitting (right) positions. Pre-operative antero-posterior standing pelvic (b) and lateral left hip (c) radiographs. Digital KA-THA templating (d). Post-operative antero-posterior supine pelvic (e) and lateral hip (f) radiographs 

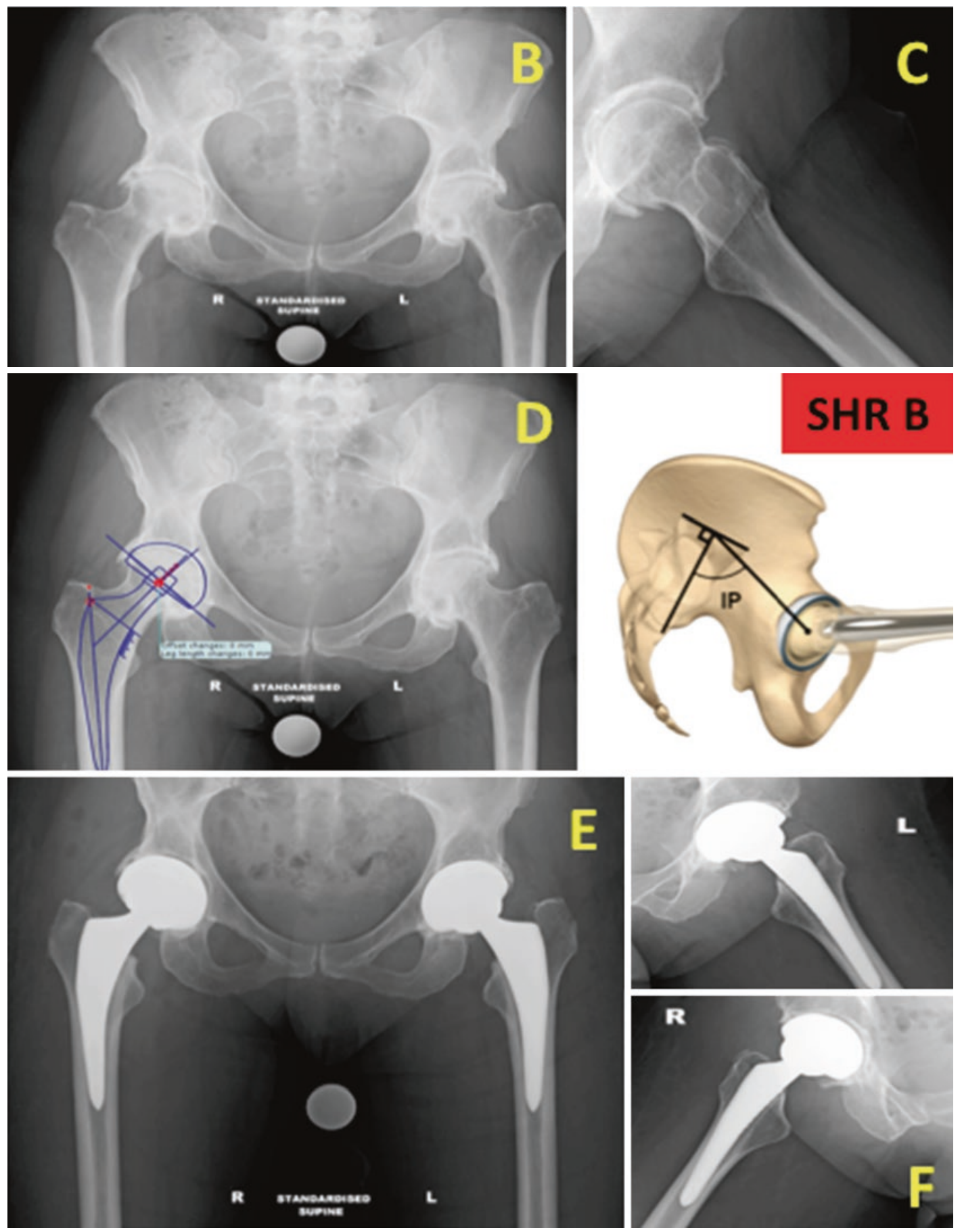

Fig. 11.13 (continued) 

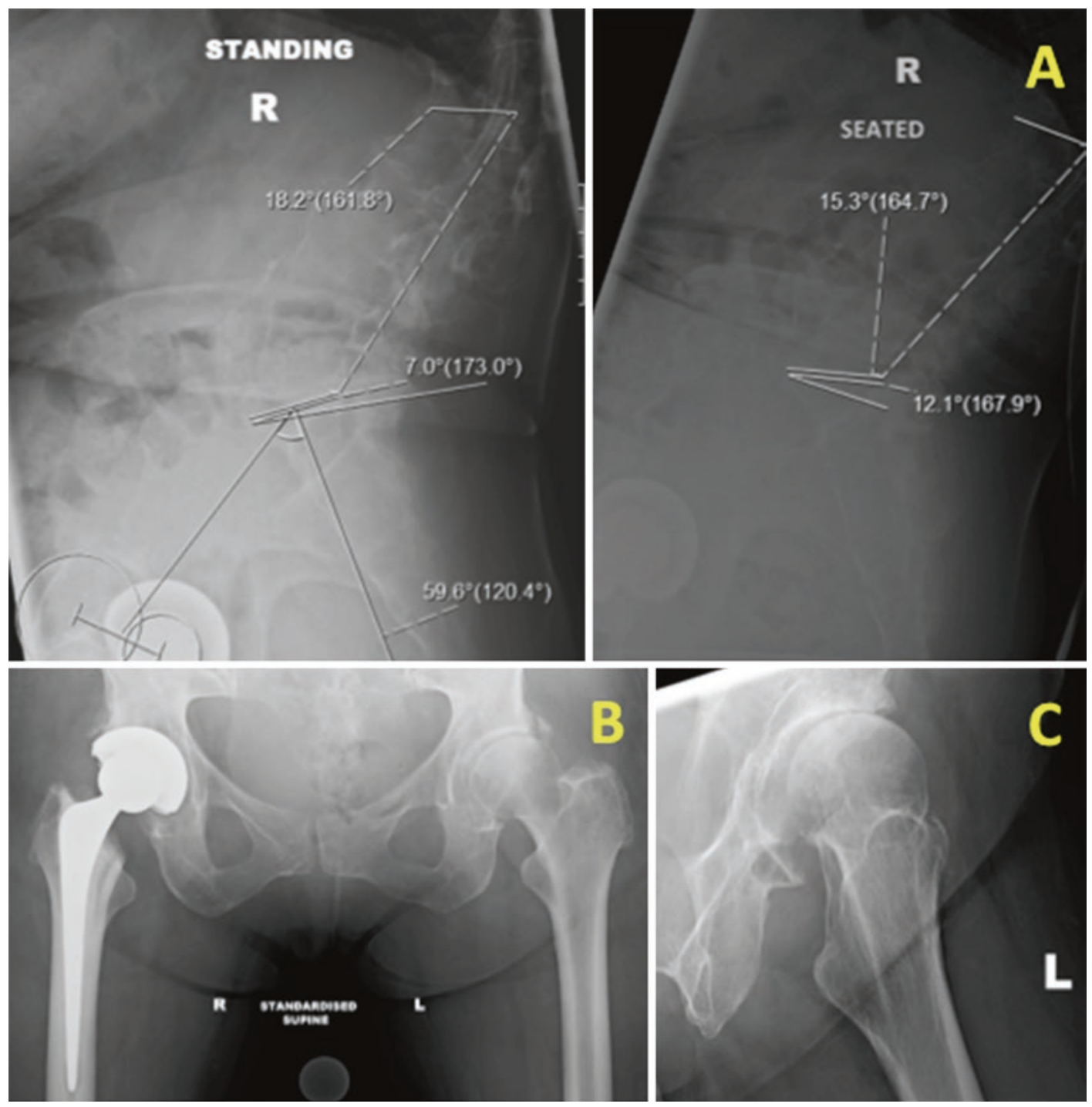

Fig. 11.14 A 79-year-old patient with severe spine degeneration and a spine-hip relationship type D (decompensated sagittal spinal imbalance). There is a normal pelvic incidence $\approx 60^{\circ}$ and low standing lumbar lordosis $\approx$ $18^{\circ}$ for $42^{\circ}$ mismatch, $41^{\circ}$ standing pelvic version (normally $20 \%$ of $\mathrm{PI}$, which is approximately $12^{\circ}$ ) suggesting the patient has $29^{\circ}$ excessive pelvic retroversion when standing. In the event of a replacement, anatomically aligning components would have been suboptimal considering the risks of poor standing component interaction (antero-superior edge loading and posterior prosthetic impingement) and anterior instability. In order to reduce those risks, the patient received a KA-THA performed through a mini-posterior approach, preserving the integrity of anterior hip soft tissue, and with an adjusted kinematically aligned dual mobility cup, $5^{\circ}$ retroverted relative to the TAL. Pre-operative lateral lumbo-pelvic radiographs (a) in standing (left) and sitting (right) positions. Pre-operative antero-posterior standing pelvic (b) and lateral left hip (c) radiographs. Digital KA-THA templating (d). Post-operative antero-posterior supine pelvic (e) and lateral left hip (f) radiographs 

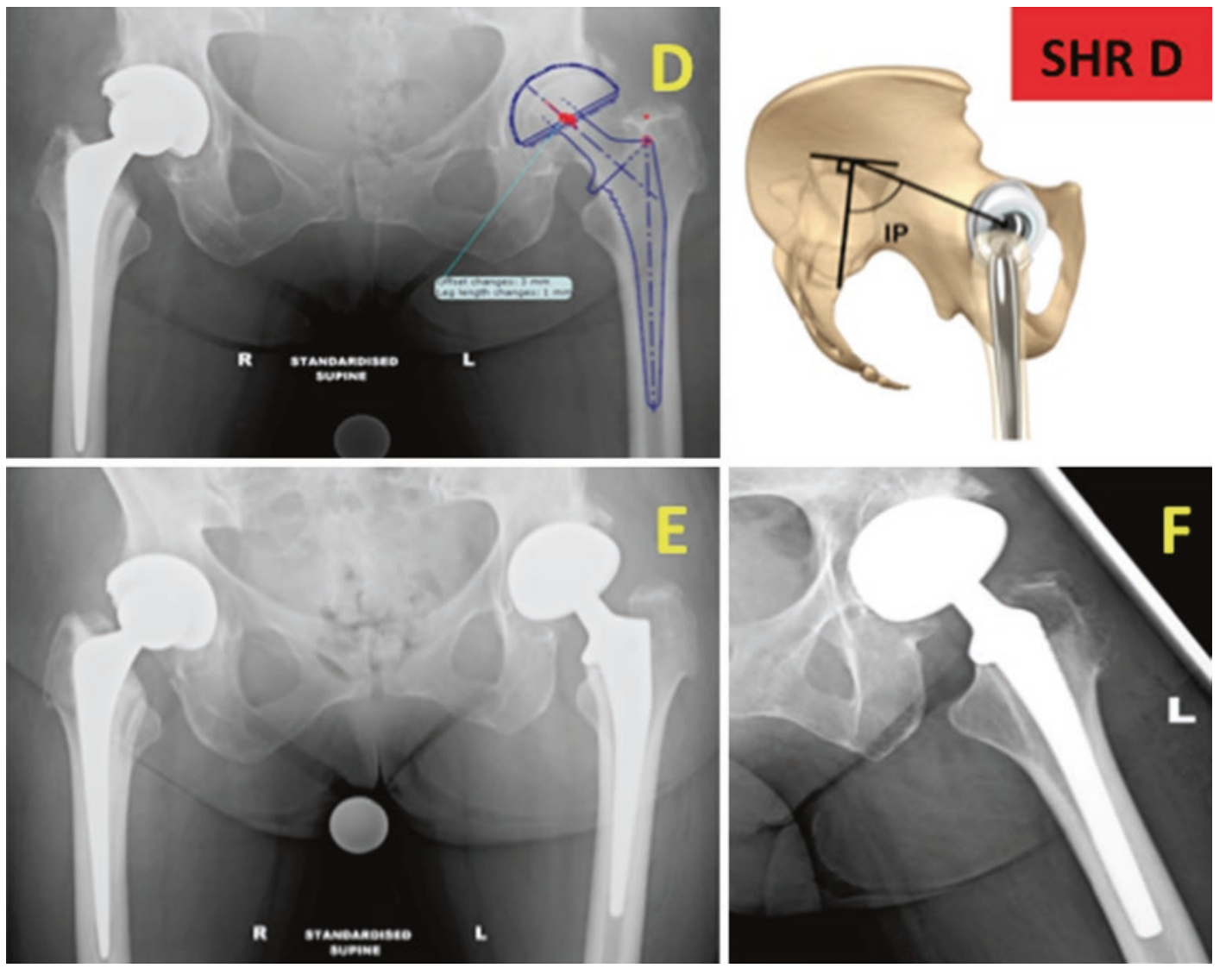

Fig. 11.14 (continued)

\section{References}

1. Rivière C, Lazennec J-Y, Van Der Straeten C, Auvinet E, Cobb J, Muirhead-Allwood S. The influence of spine-hip relations on total hip replacement: a systematic review. Orthop Traumatol Surg Res. 2017;103(4):559-68.

2. Sultan AA, Khlopas A, Piuzzi NS, Chughtai M, Sodhi $\mathrm{N}$, Mont MA. The impact of spino-pelvic alignment on total hip arthroplasty outcomes: a critical analysis of current evidence. J Arthroplast. 2018;33(5):1606-16.

3. Phan D, Bederman SS, Schwarzkopf R. The influence of sagittal spinal deformity on anteversion of the acetabular component in total hip arthroplasty. Bone Jt J. 2015;97-B(8):1017-23.

4. Lum ZC, Coury JG, Cohen JL, Dorr LD. The current knowledge on Spinopelvic mobility. J Arthroplast. 2018;33(1):291-6.

5. Rivière C, Lazic S, Villet L, Wiart Y, Allwood SM, Cobb J. Kinematic alignment technique for total hip and knee arthroplasty: the personalized implant positioning surgery. EFORT Open Rev. 2018;3(3):98-105.

6. Riviere C. Kinematic versus conventional alignment techniques for total hip arthroplasty: a retrospective case control study. Orthop Traumatol Surg Res. 2019;105(5):895-905.
7. Maillot C, Harman C, Villet L, Cobb J, Rivière C. Modern cup alignment techniques in total hip arthroplasty: A systematic review. Orthop Traumatol Surg Res. 2019;105(5):907-13.

8. Bayliss LE, Culliford D, Monk AP, Glyn-Jones S, Prieto-Alhambra D, Judge A, et al. The effect of patient age at intervention on risk of implant revision after total replacement of the hip or knee: a population-based cohort study. Lancet. 2017;389(10077):1424-30.

9. Stefl M, Lundergan W, Heckmann N, McKnight B, Ike H, Murgai R, et al. Spinopelvic mobility and acetabular component position for total hip arthroplasty. Bone Joint J. 2017;99-B(1_Supple_A):37-45.

10. Spencer-Gardner L, Pierrepont J, Topham M, Baré J, McMahon S, Shimmin AJ. Patient-specific instrumentation improves the accuracy of acetabular component placement in total hip arthroplasty. Bone Joint J. 2016;98-B(10):1342-6.

11. Rivière C, Lazic S, Dagneaux L, Van Der Straeten C, Cobb J, Muirhead-Allwood S. Spine-hip relations in patients with hip osteoarthritis. EFORT Open Rev. 2018;3(2):39-44.

12. Lazennec JY, Thauront F, Robbins CB, Pour AE. Acetabular and femoral anteversions in standing position are outside the proposed safe zone after total hip arthroplasty. J Arthroplast. 2017;32(11):3550-6. 
13. Dorr LD, Malik A, Dastane M, Wan Z. Combined anteversion technique for Total hip arthroplasty. Clin Orthop. 2009;467(1):119-27.

14. Hua X, Li J, Jin Z, Fisher J. The contact mechanics and occurrence of edge loading in modular metal-on-polyethylene total hip replacement during daily activities. Med Eng Phys. 2016;38(6):518-25.

15. Marchetti E, Krantz N, Berton C, Bocquet D, Fouilleron N, Migaud H, et al. Component impingement in total hip arthroplasty: frequency and risk factors. A continuous retrieval analysis series of 416 cup. Orthop Traumatol Surg Res. 2011;97(2):127-33.

16. Shoji T, Yamasaki T, Izumi S, Kenji M, Sawa M, Yasunaga Y, et al. The effect of cup medialization and lateralization on hip range of motion in total hip arthroplasty. Clin Biomech. 2018;57:121-8.

17. McCarthy TF, Alipit V, Nevelos J, Elmallah RK, Mont MA. Acetabular cup anteversion and inclination in hip range of motion to impingement. J Arthroplast. 2016;31(9):264-8.

18. Malkani AL, Ong KL, Lau E, Kurtz SM, Justice BJ, Manley MT. Early- and late-term dislocation risk after primary hip arthroplasty in the medicare population. $\mathrm{J}$ Arthroplast. 2010;25(6):21-5.

19. Parratte S, Ollivier M, Lunebourg A, Flecher X, Argenson JN. No benefit after THA performed with computer-assisted cup placement: 10-year results of a randomized controlled study. Clin Orthop. 2016; 474:2085-93.

20. Abdel MP, von Roth P, Jennings MT, Hanssen AD, Pagnano MW. What safe zone? The vast majority of dislocated THAs are within the Lewinnek safe zone for acetabular component position. Clin Orthop Relat Res. 2016;474(2):386-91.

21. Esposito CI, Gladnick BP, Lee Y, Lyman S, Wright TM, Mayman DJ, et al. Cup position alone does not predict risk of dislocation after hip arthroplasty. J Arthroplast. 2015;30(1):109-13.

22. Reina N, Putman S, Desmarchelier R, Sari Ali E, Chiron P, Ollivier M, et al. Can a target zone safer than Lewinnek's safe zone be defined to prevent instability of total hip arthroplasties? Case-control study of 56 dislocated THA and 93 matched controls. Orthop Traumatol Surg Res. 2017;103(5):657-61.

23. Archbold HAP, Mockford B, Molloy D, McConway J, Ogonda L, Beverland D. The transverse acetabular ligament: an aid to orientation of the acetabular component during primary total hip replacement. J Bone Joint Surg. 2006;88(7):4.

24. Girard J, Lons A, Ramdane N, Putman S. Hip resurfacing before 50 years of age: a prospective study of 979 hips with a mean follow-up of 5.1 years. Orthop Traumatol Surg Res. 2018;104(3):295-9.

25. Hill JC, Archbold HA, Diamond OJ, Orr JF, Jaramaz $\mathrm{B}$, Beverland DE. Using a calliper to restore the centre of the femoral head during total hip replacement. The J Bone Joint Surg. 2012;94(11):1468-74.

26. Girard J, Lons A, Ramdane N, Putman S. Hip resurfacing before 50 years of age: a prospective study of 979 hips with a mean follow-up of 5.1 years. Orthop Traumatol Surg Res. 2018;104(3):295-9.
27. Shin Y-S, Suh D-H, Park J-H, Kim J-L, Han S-B. Comparison of specific femoral short stems and conventional-length stems in primary cementless total hip arthroplasty. Orthopedics. 2016;39(2):e311-7.

28. Nam D, Riegler V, Clohisy JC, Nunley RM, Barrack RL. The impact of total hip arthroplasty on pelvic motion and functional component position is highly variable. J Arthroplast. 2017;32(4):1200-5.

29. Mellon SJ, Grammatopoulos G, Andersen MS, Pandit HG, Gill HS, Murray DW. Optimal acetabular component orientation estimated using edge-loading and impingement risk in patients with metal-onmetal hip resurfacing arthroplasty. J Biomech. 2015;48(2):318-23.

30. Patel AB, Wagle RR, Usrey MM, Thompson MT, Incavo SJ, Noble PC. Guidelines for implant placement to minimize impingement during activities of daily living after total hip arthroplasty. J Arthroplast. 2010;25(8):1275-1281.e1.

31. Takao M, Nishii T, Sakai T, Sugano N. Postoperative limb-offset discrepancy notably affects soft-tissue tension in total hip arthroplasty. J Bone Joint Surg. 2016;98(18):1548-54.

32. Pierrepont JW, Feyen H, Miles BP, Young DA, Baré JV, Shimmin AJ. Functional orientation of the acetabular component in ceramic-on-ceramic total hip arthroplasty and its relevance to squeaking. Bone Jt J. 2016;98-B(7):910-6.

33. Bedard NA, Martin CT, Slaven SE, Pugely AJ, Mendoza-Lattes SA, Callaghan JJ. Abnormally high dislocation rates of total hip arthroplasty after spinal deformity surgery. J Arthroplast. 2016;31(12):2884-5.

34. DelSole EM, Vigdorchik JM, Schwarzkopf R, Errico TJ, Buckland AJ. Total hip arthroplasty in the spinal deformity population: does degree of sagittal deformity affect rates of safe zone placement, instability, or revision? J Arthroplast. 2017;32(6):1910-7.

35. Dagneaux L, Marouby S, Maillot C, Canovas F, Rivière C. Dual mobility device reduces the risk of prosthetic hip instability for patients with degenerated spine: A case-control study. Orthop Traumatol Surg Res. 2019;105(3):461-6.

36. Esposito CI, Carroll KM, Sculco PK, Padgett DE, Jerabek SA, Mayman DJ. Total hip arthroplasty patients with fixed spinopelvic alignment are at higher risk of hip dislocation. J Arthroplast. 2018;33(5):1449-54.

37. Fessy MH, Putman S, Viste A, Isida R, Ramdane N, Ferreira A, et al. What are the risk factors for dislocation in primary total hip arthroplasty? A multicenter case-control study of 128 unstable and 438 stable hips. Orthop Traumatol Surg Res. 2017;103(5):663-8.

38. Bonnin MP, Archbold PHA, Basiglini L, Fessy MH, Beverland DE. Do we medialise the hip Centre of rotation in total hip arthroplasty? Influence of acetabular offset and surgical technique. Hip Int. 2012;22(4):371-8.

39. Grammatopoulos G, Alvand A, Monk AP, Mellon S, Pandit H, Rees J, et al. Surgeons' accuracy in achieving their desired acetabular component orientation. J Bone Joint Surg. 2016;98(17):e72. 
40. Pierrepont JW, Feyen H, Miles BP, Young DA, Baré JV, Shimmin AJ. Functional orientation of the acetabular component in ceramic-on-ceramic total hip arthroplasty and its relevance to squeaking. Bone Jt J. 2016;98(7):910-6.

41. Merle C, Grammatopoulos G, Waldstein W, Pegg E, Pandit H, Aldinger PR, et al. Comparison of native anatomy with recommended safe component orientation in total hip arthroplasty for primary osteoarthritis. J Bone Joint Surg. 2013;95(22):e172.

42. Thelen T, Thelen P, Demezon H, Aunoble S, Le Huec J-C. Normative 3D acetabular orientation measurements by the low-dose EOS imaging system in 102 asymptomatic subjects in standing position: analyses by side, gender, pelvic incidence and reproducibility. Orthop Traumatol Surg Res. 2017;103(2):209-15.

43. Uemura K, Takao M, Otake Y, Koyama K, Yokota F, Hamada $\mathrm{H}$, et al. Can anatomic measurements of stem anteversion angle be considered as the functional anteversion angle? J Arthroplast. 2018;33(2):595-600.

44. Rivière C, Hardijzer A, Lazennec J-Y, Beaulé P, Muirhead-Allwood S, Cobb J. Spine-hip relations add understandings to the pathophysiology of femoroacetabular impingement: a systematic review. Orthop Traumatol Surg Res. 2017;103(4):549-57.

45. Mayeda BF, Haw JG, Battenberg AK, Schmalzried TP. Femoral-acetabular mating: the effect of femoral and combined anteversion on cross-linked polyethylene wear. J Arthroplast. 2018 [cited 2018 Sep 11]. https://linkinghub.elsevier.com/retrieve/pii/ S0883540318305539.

46. Miyoshi H, Mikami H, Oba K, Amari R. Anteversion of the acetabular component aligned with the transverse acetabular ligament in total hip arthroplasty. J Arthroplast. 2012;27(6):916-22.

47. Piazzolla A, Solarino G, Bizzoca D, Montemurro V, Berjano P, Lamartina C, et al. Spinopelvic parameter changes and low back pain improvement due to femoral neck anteversion in patients with severe unilateral primary hip osteoarthritis undergoing total hip replacement. Eur Spine J. 2018;27(1):125-34.

48. Shah SM, Munir S, Walter WL. Changes in spinopelvic indices after hip arthroplasty and its influence on acetabular component orientation. J Orthop. 2017;14(4):434-7.

49. Berliner JL, Esposito CI, Miller TT, Padgett DE, Mayman DJ, Jerabek SA. What preoperative factors predict postoperative sitting pelvic position one year following total hip arthroplasty? Bone Joint J. 2018;100(10):8.

50. Zahn RK, Grotjohann S, Pumberger M, Ramm H, Zachow S, Putzier M, et al. Influence of pelvic tilt on functional acetabular orientation. Technol Health Care. 2017;25(3):557-65.

51. Ezquerra L, Quilez MP, Pérez MÁ, Albareda J, Seral B. Range of movement for impingement and dislocation avoidance in total hip replacement predicted by finite element model. J Med Biol Eng. 2017;37(1):26-34.

52. McCarthy TF, Nevelos J, Elmallah RK, Chughtai M, Khlopas A, Alipit V, et al. The effect of pelvic tilt and femoral head size on hip range-of-motion to impingement. J Arthroplast. 2017;32(11):3544-9.

53. Ohmori T, Kabata T, Maeda T, Kajino Y, Taga T, Hasegawa $\mathrm{K}$, et al. Increase in safe zone area of the acetabular cup using dual mobility cups in THA. Hip Int. 2017;27(4):361-7.

54. Philippot R, Wegrzyn J, Farizon F. Pelvic balance in sagittal and Lewinnek reference planes in the standing, supine and sitting positions [Étude de l'équilibre sagittal pelvien et du plan de Lewinnek en orthostatisme, clinostatisme et position assise]. Orthop Traumatol Surg Res. 2009;95(1):70-6.

55. Ochi H, Homma Y, Baba T, Nojiri H, Matsumoto M, Kaneko K. Sagittal spinopelvic alignment predicts hip function after total hip arthroplasty. Gait Posture. 2017;52:293-300.

56. Maratt JD, Esposito CI, McLawhorn AS, Jerabek SA, Padgett DE, Mayman DJ. Pelvic tilt in patients undergoing total hip arthroplasty: when does it matter? J Arthroplast. 2015;30(3):387-91.

57. Le Huec JC, Hasegawa K. Normative values for the spine shape parameters using $3 \mathrm{D}$ standing analysis from a database of 268 asymptomatic Caucasian and Japanese subjects. Eur. Spine J. 2016;25(11):3630-7.

58. Hill JC, Archbold HAP, Diamond OJ, Orr JF, Jaramaz $\mathrm{B}$, Beverland DE. Using a calliper to restore the Centre of the femoral head during total hip replacement. J Bone Joint Surg Br. 2012;94-B(11):1468-74.

59. Meftah M, Yadav A, Wong AC, Ranawat AS, Ranawat CS. A novel method for accurate and reproducible functional cup positioning in total hip arthroplasty. J Arthroplast. 2013;28(7):1200-5.

60. Ranawat CS, Ranawat AS, Lipman JD, White PB, Meftah M. Effect of spinal deformity on pelvic orientation from standing to sitting position. J Arthroplast. 2016;31(6):1222-7.

Open Access This chapter is licensed under the terms of the Creative Commons Attribution 4.0 International License (http://creativecommons.org/licenses/by/4.0/), which permits use, sharing, adaptation, distribution and reproduction in any medium or format, as long as you give appropriate credit to the original author(s) and the source, provide a link to the Creative Commons license and indicate if changes were made.

The images or other third party material in this chapter are included in the chapter's Creative Commons license, unless indicated otherwise in a credit line to the material. If material is not included in the chapter's Creative Commons license and your intended use is not permitted by statutory regulation or exceeds the permitted use, you will need to obtain permission directly from the copyright holder. 